\title{
A method for analysing phosphatase activity in aquatic bacteria at the single cell level using flow cytometry
}

\author{
Solange Duhamel ${ }^{\mathrm{a}, *}$, Gerald Gregori ${ }^{\mathrm{a}}$, France Van Wambeke ${ }^{\mathrm{a}}$, Romain Mauriac ${ }^{\mathrm{a}}$, Jiří Nedoma ${ }^{\mathrm{b}}$ \\ a Université de la Méditerranée, CNRS, Laboratoire de Microbiologie, Géochimie et Ecologie Marine, UMR 6117, Centre d'Océanologie de Marseille, campus de Luminy, Case 901, \\ 13288 Marseille, Cedex 09, France \\ b Biology Centre ASCR v.v.i., Institute of Hydrobiology, Academy of Sciences of the Czech Republic, Na Sádkách 7, CZ-370 05, České Budějovice, Czech Republic
}

\section{A R T I C L E I N F O}

\section{Article history:}

Received 27 March 2008

Received in revised form 13 June 2008

Accepted 18 June 2008

Available online 1 July 2008

\section{Keywords:}

Phosphatase

Bacteria

ELF97-phosphate

Flow cytometry

Cell concentration

\begin{abstract}
A B S T R A C T
It has been demonstrated that ELF97-phosphate (ELF-P) is a useful tool to detect and quantify phosphatase activity of phytoplankton populations at a single cell level. Recently, it has been successfully applied to marine heterotrophic bacteria in culture samples, the cells exhibiting phosphatase activity being detected using epifluorescence microscopy. Here, we describe a new protocol that enables the detection of ELF alcohol (ELFA), the product of ELF-P hydrolysis, allowing the detection of phosphatase positive bacteria, using flow cytometry. Bacteria from natural samples must be disaggregated and, in oligotrophic waters, concentrated before they can be analyzed by flow cytometry. The best efficiency for disaggregating/separating bacterial cell clumps was obtained by incubating the sample for $30 \mathrm{~min}$ with Tween 80 (10 $\mathrm{mg} \mathrm{l}^{-1}$, final concentration). A centrifugation step (20,000 g; $30 \mathrm{~min}$ ) was required in order to recover all the cells in the pellet (only $7 \pm 2 \%$ of the cells were recovered from the supernatant). The cells and the ELFA precipitates were resistant to these treatments. ELFA-labelled samples were stored in liquid nitrogen for up to four months before counting without any significant loss in total or ELFA-labelled bacterial cell abundance or in the ELFA fluorescence intensity. We describe a new flow cytometry protocol for detecting and discriminating the signals from both ELFA and different counterstains (4',6-diamidino-2-phenylindole (DAPI) and propidium iodide (PI)) necessary to distinguish between ELFA-labelled and non ELFA-labelled heterotrophic bacteria. The method has been successfully applied in both freshwater and marine samples. This method promises to improve our understanding of the physiological response of heterotrophic bacteria to P limitation.
\end{abstract}

Published by Elsevier B.V.

\section{Introduction}

Pelagic heterotrophic bacteria play an important role in the regulation of carbon and nutrient cycling (Azam et al., 1983; Cotner and Biddanda, 2002). Their function in regulating phosphate (P) cycling remains poorly understood and little is known about their role in P-limited systems (Moutin et al., 2002; Nedoma and Vrba, 2006). Concentrations of dissolved organic P (DOP) can exceed dissolved inorganic P (DIP) in coastal and open ocean surface waters (Monaghan and Ruttemberg, 1999; Karl and Björkman, 2002; Ruttenberg and Dyhrman, 2005), and thus can be considered, an alternative P source. Since DOP is not immediately available for bacterial and phytoplankton uptake, these organisms synthesise phosphohydrolytic ectoenzymes like alkaline or acid phosphatases to hydrolyse DOP into biologically available DIP (Hoppe, 2003).

The substrate ELF-97 [2-(59-chloro-29-phosphoryloxyphenyl)-6chloro-4-(3H)-quinazolinone] -phosphate (ELF-P) is used to detect

\footnotetext{
* Corresponding author. Present address: Center for Microbial Oceanography: Research and Education (C-MORE) and Department of Oceanography, University of Hawaii, Honolulu, HI 96822, USA. Tel.: +1 808956 0308; fax: + 8089560300.

E-mail address: solange@hawaii.edu (S. Duhamel).
}

and quantify cell-attached extracellular phosphatase activity (PA) (Nedoma et al., 2003; Dignum et al., 2004b). By enzymatic hydrolysis, the water-soluble ELF-P is converted into ELF-alcohol (ELFA) which is insoluble, specific, photostable and highly fluorescent (Huang et al., 1993) and precipitates at the site of enzyme activity. This enables phosphatase activity to be detected at the single cell level (GonzalezGil et al., 1998; Dyhrman and Palenik, 1999). Even though the phosphatase localization in planktonic organisms is not clear, it is mostly observed in the outer membrane or at least in the region closest to the periphery of the cells (Gonzalez-Gil et al., 1998 and references therein). Most studies using the ELF labelling technique concentrate on phytoplankton; a few only have been carried out on bacteria from diverse environments such as activated sludge (Van Ommen Kloeke and Geesey, 1999), bacterial colonies and biofilms (Huang et al., 1998; Espeland and Wetzel, 2001), and an acidified lake (Nedoma and Vrba, 2006). However, to our knowledge, only one study deals with marine heterotrophic bacteria (Van Wambeke et al., in press). The ELF labelling of heterotrophic bacteria in marine environments is thus in its infancy and requires further methodological development.

Flow cytometry is a promising tool to measure the ELF labelling associated to heterotrophic bacteria expressing PA. This method has 
the advantages of performing quantitative measurements on individual cells in large numbers in an appreciably short time (typically several thousand cells are analysed per sec), as well as sensitivity and lack of interference from dissolved substances (Marie et al., 1996). The method is less time consuming than using epifluorescence microscopy with automatic image analysis (Nedoma et al., 2003) and therefore, a larger number of cells and samples can be analysed. This is particularly true if there are a low percentage of labelled cells (Van Wambeke et al., in press). Analysis of ELFA-labelled cells by flow cytometry was first applied on phytoplankton (Gonzalez-Gil et al., 1998; Dignum et al., 2004a,b) following its initial development for histological applications (Telford et al., 1999). In these studies, the distinction between positive (ELFA-labelled) and negative (unlabelled ELFA) phytoplankton cells was based on the detection of both autofluorescent pigments and ELFA fluorescence (Gonzalez-Gil et al., 1998; Dignum et al., 2004a,b). In contrast, heterotrophic bacteria are not naturally fluorescent. To detect them using flow cytometry and discriminate them from inorganic particles and/or debris, it is necessary to use a counterstaining step of their nucleic acids. For that, nucleic acids are commonly stained with fluorochromes that are excited in the blue (YOYO-1, YO-PRO-1, PicoGreen, etc.) or in the blue and UV wavelengths (like SYBR series). Like ELFA (maximum emission: $530 \mathrm{~nm}$ ), these fluorochromes emit in the green wavelength. Consequently, counterstaining of ELFA-labelled cells using these fluorochromes is not an option. Indeed, the separation of the two emission spectra would be too difficult. Thus we tested two popular stains emitting over a different wavelength range: 4',6-diamidino-2-phenylindole (DAPI; max excitation: $358 \mathrm{~nm}$, max emission: $461 \mathrm{~nm}$ ) and Propidium Iodide (PI; max excitation: $535 \mathrm{~nm}$, max emission: $617 \mathrm{~nm}$ ). Cell labelling using DAPI and ELFA (max excitation: $360 \mathrm{~nm}$, max emission: $530 \mathrm{~nm}$ ), both excitable in UV but emitting at distinct wavelengths, should enable the spectral separation of the two dye emissions and thus discriminate the ELFA positive cells (both DAPI and ELFA-labelled) from the negative cells stained only with DAPI. Since intact membranes are not permeable to PI, it is also commonly used in viability studies to detect dead cells (Sgorbati et al., 1996; Grégori et al., 2001; Manini and Danovaro, 2006). The fixation of the ELFA-labelled cells by a PBS-formalin mixture (see Materials and Methods) allows PI staining of total bacterial cells. Consequently, PI should be a suitable counterstain since its emission and excitation spectra are very different from those of ELFA. This counterstain has been successfully used for the detection of lacZ mRNA in cultured fibroblasts using the ELF-P substrate (Paragas et al., 1997).

The objective of this study was to develop a simple method for detecting and quantifying ELFA-labelled heterotrophic bacteria using flow cytometry. In this method, the bacterial cells had to be concentrated, the cell clumps disaggregated and the subsequent pellet incubated with ELF-P in the liquid phase so that the sample could be adequately analysed using flow cytometry. We also describe the cytometry instrument setup and the dual labelling protocols (ELF+ DAPI and ELF+PI), showing their respective advantages/disadvantages. We checked methods for preserving ELFA labelled samples to see if it is possible to delay analysis by flow cytometry. Finally, we present some results from the applications of the proposed method in two contrasting environments: a mesotrophic lake and the oligotrophic Mediterranean Sea.

\section{Materials and methods}

\subsection{Cultures and field samples}

Bacterial cultures of the marine strain Alteromonas infernus which is able to produce the phosphatase enzyme (Van Wambeke et al., in press) were grown in artificial sea water, modified using the method of Lyman and Fleming (1940), and supplied with $\mathrm{N}$ (as $\mathrm{NH}_{4} \mathrm{Cl}$ ). The concentration of organic $\mathrm{C}$ (as pyruvate) and $\mathrm{P}$ (as $\mathrm{KH}_{2} \mathrm{PO}_{4}$ ) was restricted in order to obtain less abundant cultures and P-limited conditions. We added traces of iron and vitamins. Initial bacterial concentrations were $1-5 \times 10^{6}$ cell $\mathrm{ml}^{-1}$ for the disaggregation tests and $1 \times 10^{6} \mathrm{cell} \mathrm{ml}^{-1}$ for other tests so that all the tests could be carried out using small sample volumes ( $500 \mu \mathrm{l})$ enabling 24 samples to be processed simultaneously in a centrifuge containing micro-tubes. Cultures were continuously shaken and kept in an incubated chamber in the dark, at $20^{\circ} \mathrm{C}$.

We sampled Lake Plešné $\left(48^{\circ} 47^{\prime} \mathrm{N}, 13^{\circ} 52^{\prime} \mathrm{E}\right)$, an acidified mesotrophic lake (Kopacek et al., 2000; Nedoma et al., 2003) from South Bohemia (Czech Republic). DIP concentrations were below the detection limit $(30 \mathrm{nM})$ of the standard Strickland and Parsons' molybdate blue method (1972). A vertical profile was analysed (surface; $4 \mathrm{~m} ; 9 \mathrm{~m} ; 14 \mathrm{~m}$ and $17 \mathrm{~m}$ ) to study the variability in the proportion of ELFA-labelled cells and in the relative fluorescence per cell with depth. Lake samples were filtered onto $200 \mu \mathrm{m}$ membranes immediately after sampling and onto $1 \mu \mathrm{m}$ membranes before ELF-P incubation. This step provided us with a suitable sample for our methodological development of flow cytometry. Large cells and filaments that could otherwise clog the flow cytometer were removed.

Samples from the SOFCOM site $\left(43^{\circ} 14^{\prime} 30 \mathrm{~N} ; 05^{\circ} 17^{\prime} 30 \mathrm{E}\right)$ in the Mediterranean Sea (Marseille Bay) were taken from 5 depths $(2,10,25$, 40 and $55 \mathrm{~m}$ ) July 25th 2007. The bulk PA was measured using MUF-P (4-methylumbelliferyl-phosphate) as a substrate (see protocol in Van Wambeke et al., 2002). ELF-P incubations and DIP concentrations (MAGIC25 method, Rimmelin and Moutin, 2005) were processed in triplicate for each depth. The profiles of Chlorophyll a (Chl a) and temperature were acquired onboard using a CTD profiler.

Time kinetic experiments for ELFA labelling were carried out on surface waters of both lake and sea samples, in order to determine the incubation time necessary for routine assays.

\subsection{ELF-P incubations}

We used the Endogenous Phosphatase Detection Kit (Molecular Probes E 6601) to prepare the ELF-P solution, Component A, diluted 1/ 20 according the manufacturer recommendations.

\subsubsection{Method A: filtration method}

The filtration method was first described in Van Wambeke et al. (in press). After filtration of a live sample, the filter was transferred onto a glass slide. Forty $\mu$ l of the diluted ELF-P solution were spread onto the filter using a plastic tip. The slide was then put into a sealed horizontal $50 \mathrm{ml}$ tube with pieces of wet pad, to prevent evaporation during the incubation period (dark, room temperature). Following incubation the filter was briefly put onto a piece of absorbing paper and transferred onto an pad (AP100 Millipore) embedded with a solution of phosphate buffered saline (PBS $10 \mathrm{mM}, \mathrm{pH} 7.5$ ) with $1 \%$ formaldehyde, for $15 \mathrm{~min}$ to stop the reaction. The filter was then dried on a piece of absorbent paper before being mounted with immersion oil onto a glass slide for microscopic analysis. When needed, cells were counterstained with DAPI or PI (see below). As it is impossible to link the ELFA fluorescence observed to an individual cell using epifluorescence microscopy, we use the term "ELFA spot" for counting ELFA-labelling by microscopy.

\subsubsection{Method B: centrifugation method}

A given volume of the fresh sample was put in centrifuge tubes (2 ml Eppendorf tubes for tests on bacterial culture; $15 \mathrm{ml} \mathrm{Beckman}$ polyallomer centrifuge tubes for tests on natural samples) and centrifuged for $30 \mathrm{~min}$ at 20,000 g (Fig. 1). The supernatant was then carefully removed by aspiration with a sterile pipette. The remaining bacterial cells were incubated with $100 \mu \mathrm{l}$ of the diluted ELF-P solution, for $2 \mathrm{~h}$ in the dark, at room temperature. The reaction was stopped by adding $400 \mu \mathrm{l}$ of phosphate buffered saline solution (PBS 10 mM, pH 7.5) containing 5\% formaldehyde (e.g. 4\% final), for 


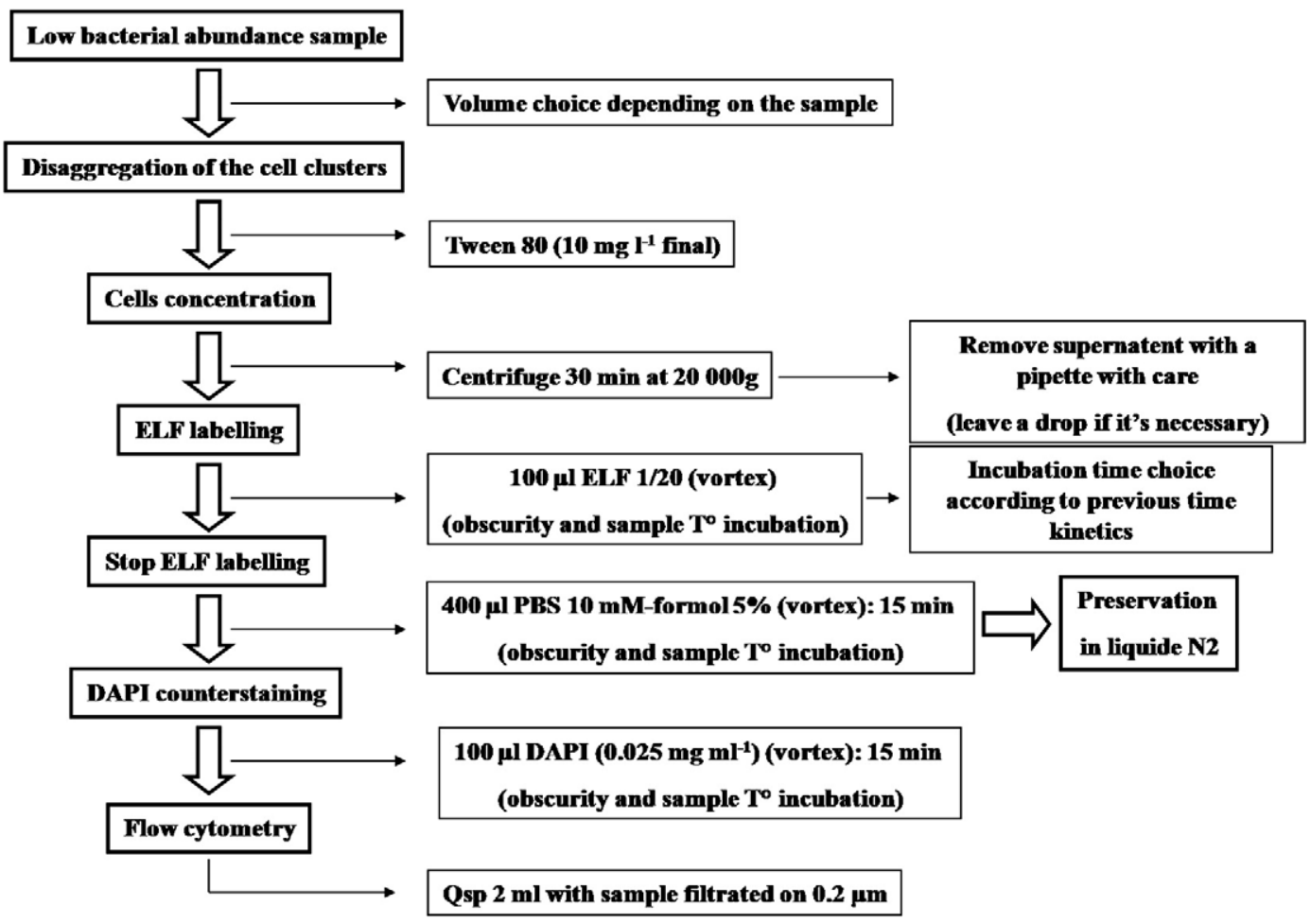

Fig. 1. A flow diagram demonstrating ELF labelling in samples with low bacterial abundance, prior to detection using flow cytometry.

$15 \mathrm{~min}$. The sample was then re-suspended in $1.5 \mathrm{ml}$ of $0.2 \mu \mathrm{m}$-filtered samples, and where necessary, the cells were counterstained with DAPI (see below) prior to filtration for microscopy or flow cytometry evaluation.

\subsubsection{Lake samples}

In the lake samples, the bacterial abundance, was high enough

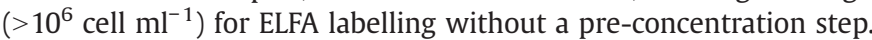
Samples were incubated with pure ELF-P substrate (E6588; $20 \mu \mathrm{M}$, final concentration) as described by Nedoma and Vrba (2006). Following incubation, $2 \mathrm{ml}$ aliquots were dispensed into cryotubes. The reaction was stopped by the addition of a phosphate buffer $\left(\mathrm{KH}_{2} \mathrm{PO}_{4} / \mathrm{K}_{2} \mathrm{HPO}_{4}\right.$, pH 6, $10 \mathrm{mM}$ final concentration) and the cells were fixed with formaldehyde ( $2 \% \mathrm{v} / \mathrm{v}$ final concentration, $15 \mathrm{~min})$. The samples were preserved in liquid nitrogen prior to analysis by flow cytometry. Blanks are $2 \mathrm{ml}$ lake samples fixed with formaldehyde (2\% $\mathrm{v} / \mathrm{v}$ final concentration) in phosphate buffer.

\subsection{Nucleic acid staining}

A DAPI or PI solution $\left(2.5 \mu \mathrm{g} \mathrm{ml} \mathrm{m}^{-1}\right.$ and $0.1 \mu \mathrm{g} \mathrm{ml} \mathrm{m}^{-1}$ final concentrations, respectively) was added to a given volume of the fixed sample. Samples were incubated with DAPI (15 min) or PI (30 min) stains in the dark and at room temperature. ELFA labelled samples following method A, were counterstained by adding $40 \mu \mathrm{l}$ of DAPI $\left(25 \mu \mathrm{g} \mathrm{ml}^{-1}\right)$ directly onto the filter and incubated for $15 \mathrm{~min}$ in the dark in $50 \mathrm{ml}$ plastic tubes containing wet paper. The dried filters were mounted using immersion oil onto glass slides for microscopic analysis.

\subsection{Tests}

\subsubsection{Disaggregation of cell clumps}

Chemical and physical treatments were tested in order to disaggregate cell clumps. For chemical treatments, the surfactant Tween 80 was used (polyoxyethylenesorbitan monooleate - Sigma).
We used five final concentrations of Tween 80: 0-0.5-1-5-10 $\mathrm{mg} \mathrm{l}^{-1}$ with five incubation times: 0-15-30-60-120 min. We also tested two physical treatments: sonication and centrifugation. Using a sonic bath (Branson 3510; $100 \mathrm{KHz}$ output) seven sonication times were tested: 0-3-10-30-90-120-180 min (room temperature) and nine centrifugation times were tested: $0-1-2-3-5-10-15-30-60 \mathrm{~min}(20,000 \mathrm{~g}$; room temperature). $500 \mu \mathrm{l}$ of culture sample were used for each test. DAPI staining was carried out in the liquid phase; samples were filtered and observed using microscopy.

\subsubsection{Cell recovery from the pellet}

Different centrifuge time/speed combinations were tested for precipitating bacterial cells: $0-5-30-45-60-120 \mathrm{~min}$ at $5500 \mathrm{~g}$ and $0-$ $30-60 \mathrm{~min}$ at $20,000 \mathrm{~g}$. A treatment corresponding to $60 \mathrm{~min}$ at $5500 \mathrm{~g}$ for samples containing $10 \mathrm{mg} \mathrm{l}^{-1}$ of Tween 80 was tested in parallel. The temperature maintained during centrifugation was that of growth conditions in the culture; i.e. $20^{\circ} \mathrm{C}$. $500 \mu$ liquots of culture were centrifuged. In each tube, the supernatant was removed and put into another sterile tube, the remaining cell pellet was re-suspended in $500 \mu \mathrm{l}$ of filtered culture medium $(<0.2 \mu \mathrm{m})$. The supernatant and the cell pellet were stained with DAPI and filtered prior to microscope counting.

\subsubsection{Effect of disaggregation and concentration treatments on ELFA spot} distribution and abundance

The effect of Tween 80 (10 $\left.\mathrm{mg} \mathrm{l}^{-1} ; 30 \mathrm{~min}\right)$ and centrifugation $(20,000 \mathrm{~g} ; 30 \mathrm{~min})$ on ELFA spot distribution and abundance were tested. A control without preliminary treatment was made. This test was made on $500 \mu \mathrm{l}$ aliquots of culture. Centrifuged samples were vortexed in order to re-suspend the cells in the supernatant prior to the filtration step. ELF labelling was achieved according to method A.

\subsubsection{Preservation}

Finally, the preservation of ELF-labelled samples was tested over an eight month storage period in liquid nitrogen. Samples of culture were labelled following method B ( $2 \mathrm{ml}$ final volume) before freezing in 
liquid nitrogen. An additional set of unlabelled samples were frozen to follow potential loss of total cells. At time zero (reference not stored at all) two controls were made: samples were analysed (1) before freezing (named T0) and (2) after $15 \mathrm{~min}$ of liquid nitrogen freezing (named T0'). We examined the storage effect by analysing samples every day for 2 days (T1 and T2) and then once a month over 8 months. Unlabelled samples were labelled with DAPI on thawing. The number and relative fluorescence (using the standard bead fluorescence) of ELFA positive cells (for ELFA-labelled samples) and the number of DAPI-stained cells (for unlabelled samples) were analysed by flow cytometry.

Samples from the preservation test were used to compare ELFA labelling with and without counterstaining. These samples were divided into 3 aliquots before analysis by flow cytometry. One aliquot was processed immediately; the 2 others were counterstained either with DAPI or PI, as described above, in order to test the effect of dual labelling on ELFA-labelled cell abundance.

\subsection{Microscopic analysis}

The filters ( $0.2-\mu \mathrm{m}$ black polycarbonate filters) were mounted using an Olympus immersion oil for fluorescence (nd 1.404), onto glass slides with cover slips. ELFA spots and DAPI positive cells were counted with an Olympus BH2 microscope equipped with a long pass cube type $\mathrm{U}$ (dichroic mirror DM 400, barrier filter L420). Photographic images were obtained using an E series digital camera (Apogee Instruments Inc.) linked to Image Pro-Plus software (Scope-pro 5.0). Thirty fields with a minimum of 30 cells were counted per filter.

\subsection{Flow cytometry analysis}

Flow cytometry analysis were carried out on a MoFlo cell sorter (Dako, Dk) equipped with a water cooled Argon laser providing $352 \mathrm{~nm}$ (UV) and $488 \mathrm{~nm}$ (blue) laser beams set at a regulated $50 \mathrm{~mW}$ output power for UV. Each cell was characterized by 5 optical parameters: two scatter parameters based on the $488 \mathrm{~nm}$ laser beam, namely forward angle light scatter (related to the particle size) and right angle light scatter (related to cell structure and shape), and three fluorescence parameters related to emissions of ELFA $(530 \pm 40 \mathrm{~nm})$ and DAPI $(405 \pm 30 \mathrm{~nm}$ or $485 \pm 25 \mathrm{~nm}$, in configuration 1 and 2, respectively, see chapter 2.7 . for the filter settings) after UV excitation, or PI $(580 \pm 30 \mathrm{~nm})$ after the $488 \mathrm{~nm}$ excitation. All the parameters were acquired in logarithmic scale. Acquisition was triggered on the right angle light scatter. ELFA positive and negative bacteria were discriminated and counted on the cytogram ELFA fluorescence intensity versus DAPI or PI fluorescence intensity (Fig. 5). The autotrophic picoplankton was gated out from the heterotrophic bacteria by using the red fluorescence of the chlorophyll collected on the third photomultiplier tube (FL3) after a $640 \mathrm{~nm}$ long pass filter.

The sheath tank was filled with $0.2 \mu \mathrm{m}$ filtered distilled water. Sheath pressure was kept constant at 60.0 PSI, and sample pressure at 60.1 PSI. In order to avoid doublets and hard coincidences, the flow rate was kept lower than 8000 events $\mathrm{s}^{-1}$. A minimum of 50,000 bacterial cells were analysed per sample. Analyses were performed during 1 or $2 \mathrm{~min}$. The exact volume analysed was derived from a preliminary calibration phase during which a sample was weighed before and after a 3 min analysis in order to determine the average flow rate (in $\mu \mathrm{s}^{-1}$ ). The procedure was repeated 3 times and the average flow rate calculated.

All parameters are in arbitrary units. In order to compare the data between samples and to determine the ELF relative fluorescence of each particle (bacteria), a solution of $2 \mu \mathrm{m}$-beads (Fluoresbrite, Polysciences, USA) was added to the samples. These beads are blue and UV-excitable and emit both in the DAPI and ELFA emission wavelength range. The relative median fluorescence per cell of cells labelled with ELFA was determined by dividing the median fluorescence intensity of ELFA-labelled cells in the ELF channel (in arbitrary units per cell, A.U. cell ${ }^{-1}$ ) by the median fluorescence intensity of beads in the same channel. Absolute ELFA fluorescence (in arbitrary units per ml, A.U. $\mathrm{ml}^{-1}$ ) corresponds to the product between median cell associated ELFA fluorescence and the number of ELFA-labelled cells.

\subsection{Flow cytometry filter settings}

DAPI (Ex/Em: 358/461 nm) and ELFA were both excited by UV light and showed an overlap of their emission spectra (Fig. 4). We tested two filter configurations in order to obtain the best signal separation. In the configuration 1 (Fig. 4), we separated the DAPI emission by a $440 \mathrm{~nm}$ longpass dichroic mirror that reflects wavelengths lower than $440 \mathrm{~nm}$, followed by a $405 \pm 30 \mathrm{~nm}$ bandpass filter set up just before the photomultiplier tube detector. The power of the UV laser $(50 \mathrm{~mW})$ was high enough to collect a sufficient signal using the $405 \pm 30 \mathrm{~nm}$ band-pass filter, whereas the maximal DAPI emission was centered around $461 \mathrm{~nm}$. The wavelengths transmitted through the $440 \mathrm{~nm}$ dichroic mirror arrived at a $530 \pm 40 \mathrm{~nm}$ filter to separate and collect the ELFA signal on the photomultiplier tube number 5 . In the configuration 2, we separated the DAPI and ELFA emissions by a $505 \mathrm{~nm}$ dichroic shortpass filter that enabled a wavelength lower than $505 \mathrm{~nm}$ to be collected by the photomultiplier tube number 5 after filtration through a $485 \pm 25 \mathrm{~nm}$ filter (for DAPI signal) and reflected wavelengths higher than $505 \mathrm{~nm}$ that were filtered by a $530 \pm 40 \mathrm{~nm}$ filter (for ELFA signal) before detection by the photomultiplier tube number 4 (for ELF signal). Since PI (Ex/Em: 535/617 nm) and ELFA (Ex/ Em: $345 / 530 \mathrm{~nm}$ ) were excited by two non-collinear laser beams (blue and UV lines, respectively), no interference could occur during the signal acquisition of the two stains. We chose the optimum filters available, i.e. those as close as possible to the maximal emission for both ELFA and PI, for the acquisition of PI and ELFA fluorescence intensities (i.e. $580 \pm 30$ and $530 \pm 40 \mathrm{~nm}$, respectively) in the two described configurations.

\subsection{Data analysis}

All tests were performed using 5 replicates per treatment except for the preservation of ELF labelled sample test and for in-situ applications, which were performed with 3 replicates per treatment. The statistical significance of differences in many treatments was evaluated using Kruskal-Wallis test (to compare more than 2 treatments) or Wilcoxon-Mann-Whitney test (to compare 2 treatments). All tests were performed using the software Sigma Plot V9.01. Data are presented under the form mean \pm standard deviation.

Flow cytometry data were acquired and analysed with the Summit V4.3 software (Dako, Dk). "Gating" refers to the process of selecting a subset of events on a graph for further data analysis on other graphs. This function allows a better discrimination of the cluster(s) of interest on different cytograms (i.e. in function of different parameters). The spectral overlap between ELFA and DAPI fluorochromes makes compensation necessary. Compensation is the process by which the fluorescence "spillover" originating from a fluorochrome other than the one specified for a particular photomultiplier tube is subtracted as the percentage of the signal from other photomultiplier tube. This treatment was processed with the Summit V4.3 software function "compensate". Because a digital compensation was performed, the raw data were not affected.

\section{Results}

\subsection{Disaggregation of cell clumps}

Microscopic inspection (Fig. 2) confirmed that the Tween 80 treatment was efficient in separating the cell clumps. The number of free bacteria and aggregates increased significantly with the addition of 


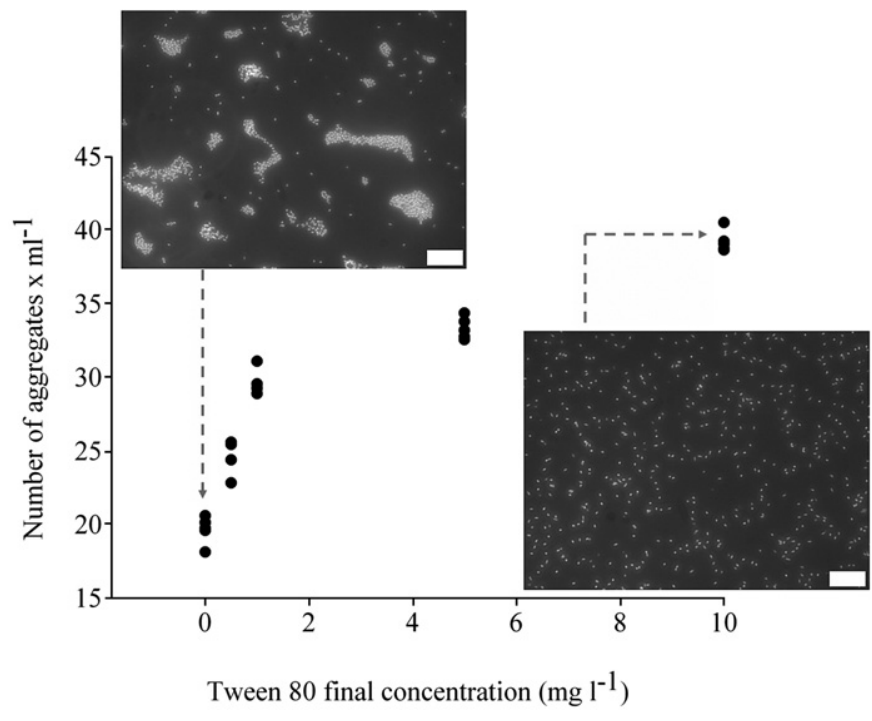

Fig. 2. Variation in the number of aggregates counted with epifluorescence microscopy using different final concentrations of Tween 80 over a 30 min incubation time. Examples of pictures obtained with slides without and with $10 \mathrm{mg} \mathrm{l}^{-1}$ of Tween 80 . White scale bar corresponds to $10 \mu \mathrm{m}$.

Tween 80, up to a final concentration of $10 \mathrm{mg} \mathrm{l}^{-1}$, from $(2.7 \pm 0.22) \times 10^{6}$ in the control to $(5.3 \pm 0.25) \times 10^{6}$ free cells $\mathrm{ml}^{-1}(p<0.05$; data not shown $)$ and from 20 to 40 aggregates $\mathrm{ml}^{-1}(p<0.05$, Fig. 2 ). Consequently, using $10 \mathrm{mg} \mathrm{l}^{-1}$ of Tween 80 gave the greatest ratio of free/attached bacteria $(0.3 \pm 0.1)(p<0.05)$, without apparent cell loss $(p<0.05$; the total number of cells were counted for each treatment, data not shown). Testing the incubation time, we found that the number of free bacteria significantly increased from $(1.6 \pm 0.45) \times 10^{6}$ (control) to $(4.8 \pm 0.13) \times 10^{6}$ cells ml $^{-1}$, reaching a plateau after a $30 \mathrm{~min}$ incubation ( $p<0.05$; data not shown).

Sonication in a water bath did not give any increase in the free/attached ratio until $90 \min (p<0.05)$. Worse than this, it led to a significant decrease in total bacteria counts $(p<0.05)$ and gave an increase in the filter background (data not shown). Centrifuging at 20,000 g showed an unexpected, but rather interesting, increase in the free/attached ratio after $30 \mathrm{~min}(18 \pm 5 \%)$ and again after $60 \mathrm{~min}(36 \pm 12 \%)$ when compared to the control (data not shown).

\subsection{Cell recovery after centrifugation}

In order to provide quantitative results for ELF labelling, it is necessary to minimise cell losses occurring in the centrifugation/ precipitation step. Firstly, we tested speed of $5500 \mathrm{~g}$ (maximum allowed for 15-ml tubes on our 3K15 Sigma centrifuge which is usable on vessel during cruises) to precipitate cells. Results showed that even after $120 \mathrm{~min}$ of centrifugation, $31 \pm 5 \%$ of the cells were still in the supernatant (Fig. 3) and there were significant loss in the total counts. As the addition of a surfactant is known to increase cell recovery (Biegala et al., 2003) we tested the effect Tween 80 during centrifugation. In samples centrifuged for $60 \mathrm{~min}$ at $5500 \mathrm{~g}$ with Tween, the number of cells recovered from the supernatant was reduced to $37 \pm 3 \%$ as opposed to $51 \pm 3 \%$ cells for samples with no Tween (Fig. 3). Although the addition of the surfactant during centrifugation was effective, it was not sufficient to recover enough cells for quantitative measurements. Thus, finally, we increased the centrifugation speed to $20,000 \mathrm{~g}$. Following $30 \mathrm{~min}$ of centrifugation (Fig. 3 ) only $7 \pm 2 \%$ of the cells were recovered in the supernatant. There was no statistical difference between 30 and $60 \mathrm{~min}$ of centrifugation in the proportion of cells present in the supernatant but there was a significant cell loss following 60 min compared to the uncentrifuged control ( $20 \pm 8 \%$ of cells; $p<0.05$ ).
3.3. Effect of disaggregation and concentrating on ELFA spot distribution and abundance

Treating the sample with Tween 80 (10 $\mathrm{mg} \mathrm{l}^{-1}$; $\left.30 \mathrm{~min}\right)$ and centrifuging (20,000 g; $30 \mathrm{~min})$ did not significantly affect the ELFA spot abundance $(n=5, p<0.05$, data not shown,). Qualitatively, the addition of Tween reduced the green background generally observed following ELF-labelling using method A. Moreover, using both treatments together (Tween, then centrifugation) gave a better repartition of the ELF-spots on the filter, making counting easier.

\subsection{Stopping ELF labelling reaction}

We verified that the addition of Tween 80 and the action of centrifugation did not result in unspecific labelling (i.e. in the dissolved fraction). We removed the bacteria by filtering $1 \mathrm{ml}$ of culture through $0.2 \mu \mathrm{m}$ and submitted the filtrate to protocol B. We did not observe any non-specific labelling (microscopy analysis, data not shown) as confirmed in other studies (Paragas et al., 1997; Cox and Singer, 1999).

One of the applications of this method could be the study of time kinetics of ELF labelling. For that, it is essential to have a good protocol that can stop the reaction at a precise time. Van Wambeke et al. (in press) used a solution of PBS ( $10 \mathrm{mM}, \mathrm{pH} 7.5$ ) with $1 \%$ formaldehyde to stop the reaction on the filter (method $A$ ). Thus, we first tested fixation of samples prepared according to method B, by adding $400 \mu \mathrm{l}$ of PBS-formaldehyde $1 \%$ to the tubes containing the cell pellets plus $100 \mu$ l of ELF-P $(1 / 20)$. Whilst no labelling was observed when filtration was processed immediately after addition of PBS-formaldehyde, there was significant labelling where filtration had been delayed by $15-30$ min (microscopy analysis, data not shown). Thus we used a higher concentration of formaldehyde; PBS (10 mM, pH 7.5) containing 5\% formaldehyde (i.e. 4\% final concentration). No labelling was observed by microscopy (data not shown), even when delaying the filtration step, and whatever the temperature of incubation (room temperature, $4{ }^{\circ} \mathrm{C}$ or $-20{ }^{\circ} \mathrm{C}$ ). Consequently, this protocol was used to stop ELF-labelling.

\subsection{Flow cytometry filter settings and dual labelling}

Background tests were processed to check that the products used in the labelling protocol (culture medium, DAPI, ELF, PI, Tween or PBSformaldehyde) did not produce noise in the regions of ELF and, or DAPI or PI-labelled cells fluorescence. The results showed no significant

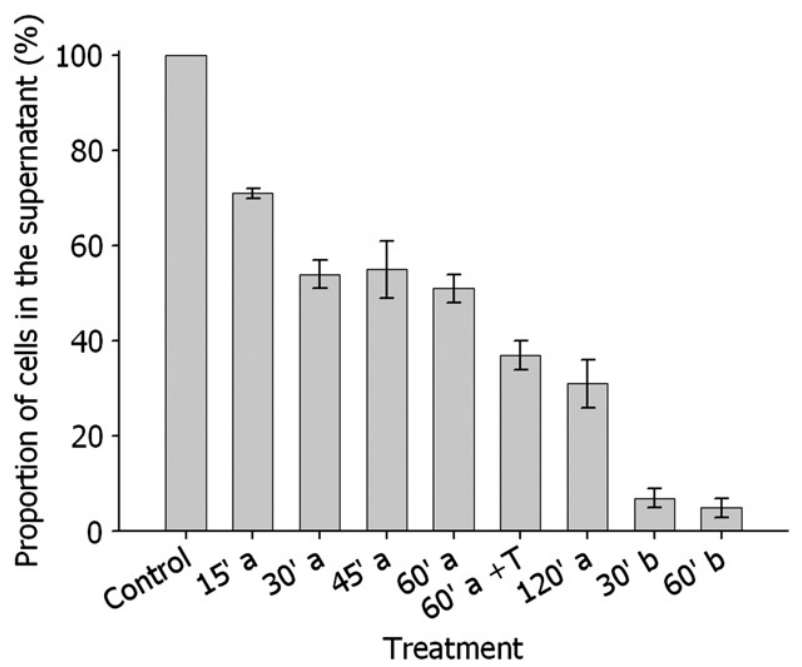

Fig. 3. Variation in the proportion of cells (\%) found in the supernatant with different centrifugation treatments. The control samples have no centrifugation step. Centrifugation times: $15^{\prime}-30^{\prime}-45^{\prime}-60^{\prime}$ and $120^{\prime}$ are expressed in minutes, a and b represent centrifugation speeds of 5500 and $20,000 \mathrm{~g}$ respectively and T represents samples containing Tween $80\left(10 \mathrm{mg} \mathrm{l}^{-1}\right)$. Error bars are sd associated with 5 replicate samples. 


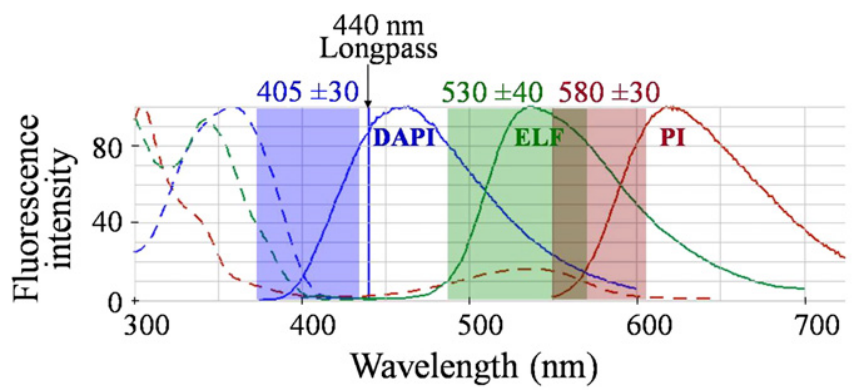

Fig. 4. Emission and excitation spectrums of ELF, DAPI and PI with areas corresponding to acquisition windows of the filter settings used in configuration 1.

background on the cytograms whatever the treatment (data not shown). Indeed, the signal obtained for background samples fall in the first decade, the typical noise area of the cytogram (between 0 and 10 arbitrary units) of fluorescence.

Two filter configurations were tested. We examined in both cases the results obtained by labelling with ELF only, with ELF+DAPI and with ELF+PI. Using configuration 1 to detect bacteria labelled with ELF only, we distinguished 2 populations on the cytogram (Fig. 5a): a population located in the area corresponding to the noise $(E L F<10 \mathrm{~A}$. U.; DAPI $<10$ A.U.) and a population with significant ELFA fluorescence and no significant fluorescence in the DAPI channel (ELF>10 A.U.; DAPI $<10$ A.U.). Using configuration 1 to detect bacteria labelled with ELF+DAPI, DAPI emissions were measured in the part of the spectrum that is not supposed to overlap with ELFA emission spectrum (Fig. 4). Nevertheless, a part of the DAPI signal leaks into the ELF channel (observed on the cytograms, data not shown). However, the software compensation treatment (see materials and methods) was efficient for separating the two signals as we obtained two distinct populations on the cytograms: a population with significant fluorescence in the ELF and DAPI channels (ELF>10 A.U.; DAPI > 10 A.U.) and a population with significant fluorescence in the DAPI channel but with no significant fluorescence in the ELF channel (ELF $<10$ A.U.; DAPI $>10$ A.U., Fig. 5b).

Using configuration 2 it was not possible to separate the ELF and DAPI signal, even with the compensation treatment, as a unique population was observed on the cytograms. Thus, configuration 1 was taken as the optimal setting for ELF+DAPI dual labelling.

The signals from ELF and PI were easily distinguishable. As for DAPI, a population with significant fluorescence in the ELF and PI channels (ELF>10 A.U.; PI>10 A.U.) and a population with significant
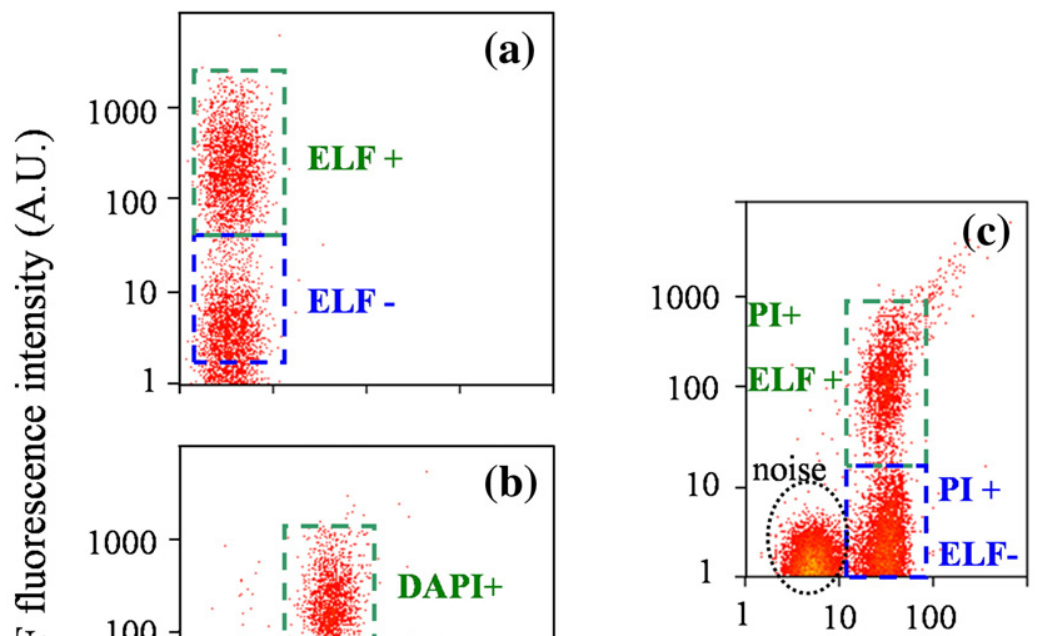

\section{PI fluorescence intensity (A.U.)}

DAPI +<smiles>ICCI</smiles>

\section{DAPI fluorescence intensity (A.U.)}
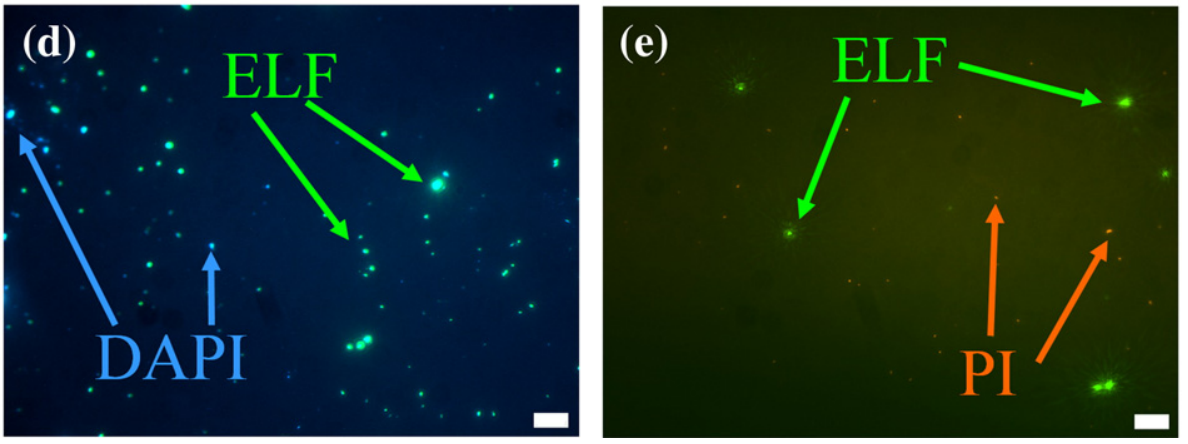

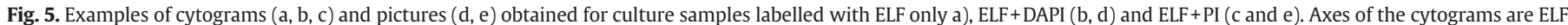

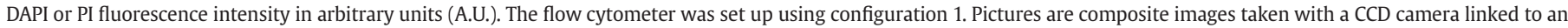

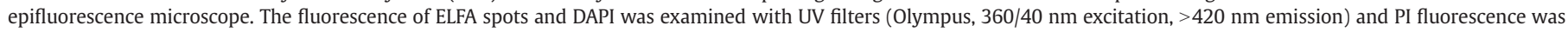
examined with a green filter (Olympus, 480/30 excitation, 535/40 emission). White scale corresponds to $10 \mu \mathrm{m}$. 


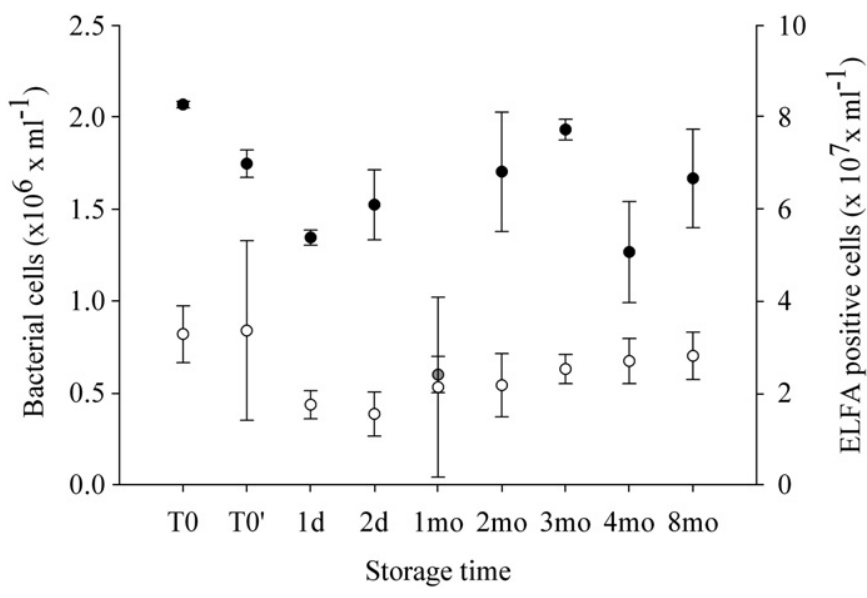

Fig. 6. Bacterial (black dots) and ELFA positive cells (white dots) counted by flow cytometry following different storage times. T0: ELF-labelled samples analysed before freezing T0': ELF-labelled samples analysed following $15 \mathrm{~min}$ of liquid nitrogen freezing, d:days, mo: months. Error bars are associated with triplicate samples. The outlier at $1 \mathrm{mo}$ for bacterial cells (grey dot) was rejected from the statistical analysis.

fluorescence in the PI channel but with no significant fluorescence in the ELF channel (ELF $<10$ A.U.; PI $>10$ A.U., Fig. 5c) were identified. The same total counts of bacterial cells were obtained for single (i.e. PI only) and dual (i.e. ELF+PI) labelled samples.

We checked that the results of ELFA labelling using configuration 1 were not influenced by the counterstaining. We compared data from the preservation tests for samples labelled with ELF only with those obtained with ELF+DAPI or ELF+PI (data not shown). We found significant correlations between treatments $(r=0.95$ and 0.94 for ELF versus ELF+PI and ELF versus ELF+DAPI, respectively; $n=21, p<0.001$ ). The regression slopes between ELFA labelled cells counted by flow cytometry for the different treatments were not significantly different from $1(p<0.001)$ All the following results were acquired using configuration 1.

\subsection{Sample storage}

No significant decrease in bacterial abundance or ELFA positive cell counts was found following an 8 months storage in liquid nitrogen $(n=27$, $p<0.001$; Fig. 6). The stability of the particle-associated relative intensity of ELFA fluorescence was verified from $\mathrm{T} 0$ to $\mathrm{T} 6$ experiments (i.e. during 4 months of storage; median relative fluorescence $=0.127 \pm 0.02$ arbitrary units, $n=24, p<0.001$ ). A significant decrease was observed for T7 (i.e. after 8 months of storage; median relative fluorescence $=0.06 \pm 0.00$ arbitrary units, $n=3$ ).

\subsection{In situ applications}

From the results of a time kinetic experiment (data not shown), we chose to incubate the vertical profile samples of Lake Plešné with ELF-P for $2 \mathrm{~h}$ (Fig. 7a). The proportion of ELFA-labelled cells was $32 \pm 2 \%$ in all samples $(p<0.05)$, except at $14 \mathrm{~m}$ where significantly higher values were recorded ( $37 \pm 0 \%$ of ELFA-labelled cells; $p<0.05$ ). The relative median fluorescence per cell, of cells labelled with ELFA, increased between the surface $\left(0.27 \pm 0.01\right.$ A.U. cell $\left.{ }^{-1}\right)$ and $9 \mathrm{~m}(0.29 \pm 0.01$ A.U. cell $^{-1}$ ) before decreasing to $0.25 \pm 0.01$ A.U. cell ${ }^{-1}$ (at $17 \mathrm{~m}$ ). At $14 \mathrm{~m}$, the relative median fluorescence per cell, of cells labelled with ELFA, was $0.28 \pm 0.01$ A.U. cell ${ }^{-1}$.

For marine samples, we were able to detect significant ELFA labelling when bulk phosphatase activity measured with MUF-P showed maximum hydrolysis rate $(\mathrm{Vm})$ values $>7 \mathrm{nM} \mathrm{h}^{-1}$. That was the case at the SOFCOM site (230-3250 events per min in the area of positive cell detection). From the results of a time kinetic experiment (data not shown), we chose to incubate the vertical profile samples of SOFCOM site with ELF-P for $6 \mathrm{~h}$ (Fig. 7b). The proportion of ELFAlabelled cells showed little variation with depth ranging from $0.8 \pm$ $0.3 \%$ at $10 \mathrm{~m}$ to $1.4 \pm 1.03 \%$ at $60 \mathrm{~m}$. The proportion of ELFA positive, high DNA cells, were 2 to 3 times higher than the proportion of total ELFA-positive cells. Despite there was no significant difference between depths in term of the proportion of ELFA-labelled cells, ELFA median fluorescence was significantly higher between 2 and $10 \mathrm{~m}\left(0.32 \pm 0.03\right.$ and $0.33 \pm 0.03$ A.U. cell ${ }^{-1}$, respectively) and interestingly peaked at $40 \mathrm{~m}\left(0.36 \pm 0.03\right.$ A.U. cell $\left.{ }^{-1}\right)$ where the highest value of bulk $\mathrm{PA}\left(\mathrm{Vm}=29.8 \mathrm{nM} \mathrm{h}^{-1}\right)$ and the minimum value of DIP concentration $(9 \pm 1.1 \mathrm{nM})$ were found. At $40 \mathrm{~m}$ depth we also measured the maximum Chla concentration $\left(10.5 \mathrm{mg} \mathrm{m}^{-3}\right)$ and abundance of Synechococcus and Prochlorococcus cells (data not shown). Nevertheless these picophytoplanktonic cells were not significantly ELFA-labelled.

(a)

(b)

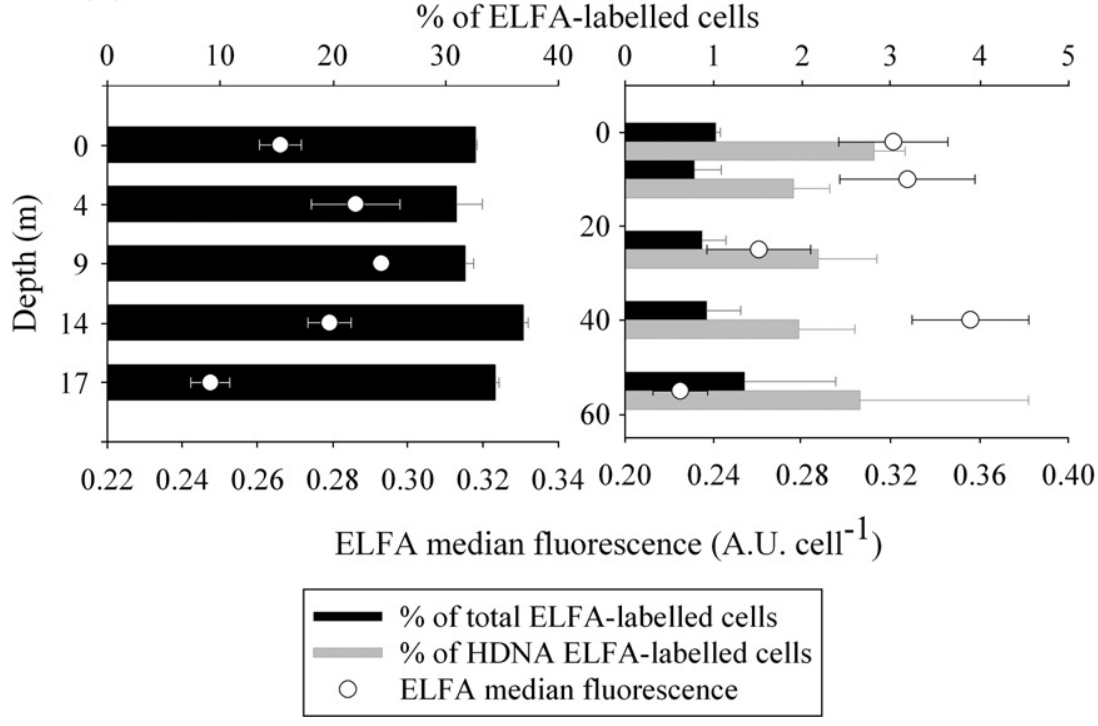

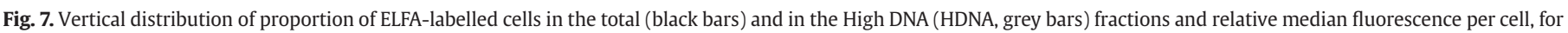
cells labelled with ELFA (white dots; A.U. cell ${ }^{-1}$ ) in Lake Plešné (a) and at SOFCOM site in Mediterranean (b). Error bars represent the standard deviation between triplicates. 


\section{Discussion}

\subsection{Sample preparation and preservation}

Contrary to epifluorescence microscopy, flow cytometry analysis requires liquid samples, which makes necessary to label the cells with ELF-P in a liquid phase. In oligotrophic areas, bacterial abundances can be low (Subtropical North Pacific Ocean: 2.3-7.4 $\times 10^{5} \mathrm{cell} \mathrm{ml}^{-1}$, Campbell

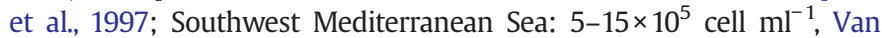
Wambeke et al., 2004; Southwest Atlantic Ocean: 2.1-9.7 $\times 10^{5} \mathrm{cell} \mathrm{ml}^{-1}$, Andrade et al., 2004). In these areas, it would be necessary to use large quantities of ELF-P in order to incubate the substrate in the sample, as previously described (Van Ommen Kloeke and Geesey, 1999; Nedoma and Vrba, 2006) and this would be prohibitively expensive. Concentrating the low bacterial abundance samples prior to ELF-labelling, provides a simple yet effective method and avoids the use of excessive reagents (Van Wambeke et al., in press). Cell concentration by centrifugation is a common technique (Larsson et al., 1978; Robertson et al., 1998; Dyhrman and Palenik 1999; Dignum et al., 2004b). The rotation speed to pellet all the bacteria in a sample must be high, and this can damage the cells. Using the heterotrophic strain Alteromonas infernus in culture or marine seawater samples (data not shown), a rotation speed of 20,000 g was necessary to precipitate bacterial cells. We did not observe significant, detrimental effect on total or ELF labelled cell counts. Nevertheless the centrifugation speed necessary to pellet all bacterial cells is much higher than speed used to pellet phytoplankton (3000 g: Dyhrman and Palenik 1999; 2000 g: Dignum et al., 2004b; 4000 g: Rengefors et al., 2003; Ou et al., 2006). These great differences in centrifugation speeds will make it difficult to find a protocol which can concentrate phytoplankton and heterotrophic bacteria in the same sample without cell loss. For now it is necessary to proceed with two independent samples.

In both natural samples and cultures, cell clumping can be a major obstacle in identifying cells using flow cytometry (Davey and Kell, 1996; Biegala et al., 2003) or epifluorescence microscopy (Bianchi and Giuliano, 1996). Therefore, the first step was to find a method for disaggregating/ separating bacterial cell clumps, without affecting ELF labelling. In our case, a surfactant was used before fixation, before ELF labelling and before centrifugation, the aim also being to aid centrifugation. As PA is reduced when Pi is added to a sample (Dyhrman and Palenik 1999; Mulholland et al., 2002), a surfactant containing very low Pi concentration must be used. Thus Tween 80 was chosen $(<0.005 \% \mathrm{P}-$ Sigma-Aldrich). The best results were found using a $10 \mathrm{mg} \mathrm{l}^{-1}$ final concentration and incubating for $30 \mathrm{~min}$. This surfactant disperses cell clumps but also facilitates even bacterial distribution on the filters (Epstein and Rossel, 1995) and a decrease in background counts was also observed.

Unless ELFA-labelled samples can be analysed immediately, they must be preserved until analysis. According to Troussellier et al. (1995), only liquid nitrogen allows mid-term ( $>4$ months) preservation and limits the evolution of DAPI-induced fluorescence and scatter characteristics (DAPI is added just before flow cytometry injection). These authors also showed that adding fixatives (best results with formaldehyde) was necessary to obtain exhaustive counts of all the bacteria cells due to the permeation effect of fixatives which gives a better staining of the cells. As previously found by Troussellier et al. (1995), we found no significant $(p<0.001)$ decrease in bacterial cell counts over time (8 months). We found no significant $(p<0.001)$ decrease in ELFA spot counts (Fig. 6) but we measured a significant decrease in ELFA relative fluorescence after 4 months (data not shown). Similarly, Nedoma et al. (2003) found no significant loss of ELFA fluorescence for filtered samples stored over 108 days at $-20^{\circ} \mathrm{C}$. Thus it is possible to store the samples for a mid-term period ( 4 months) without significant ELF-labelling loss.

\subsection{Detecting ELFA by flow cytometry}

The detection of the ELFA signal by epifluorescence microscopy has been shown to be efficient for phytoplankton (Dyhrman and Palenik
1999; Nedoma et al., 2003) and bacterioplankton (Nedoma and Vrba, 2006; Van Wambeke et al., in press). Nevertheless, it is a time consuming method (Nedoma et al., 2003). Compared to microscopic techniques, flow cytometry offers the advantages of speed, better objectivity and greater accuracy. Flow cytometry has been shown to be a fast and efficient method for phytoplankton detection of ELFA signals (Gonzalez-Gil et al., 1998; Dignum et al., 2004a,b) but, to our knowledge, it has never been applied to heterotrophic bacteria. Due to their autofluorescence, the detection of phytoplanktonic organisms does not need counterstaining in order to observe both ELFA positive and negative cells, this is not the case for heterotrophic bacteria. Van Wambeke et al. (in press) and Nedoma and Vrba (2006) used DAPI, which is one of the most common fluorochromes used to stain heterotrophic bacteria prior to detection by epifluorescence microscopy (Robertson and Button 1989; Kepner and Pratt 1994). In order to detect heterotrophic bacteria expressing phosphatase activity using image analysis, the Nedoma and Vrba (2006) method involves taking two pictures per filter field (one with DAPI and one with ELF dichroic mirrors), and superimposing them to determine the ELFA positive and negative cells. Thus, contrary to microscopy combined with image analysis, we propose a method for obtaining all the cell characteristics, including different fluorescence properties, for individual cells, in only one acquisition step. The multivariate data analysis enabled us to easily and efficiently separate ELFA-positive from ELFA-negative cells, whilst it was tedious using image analysis due to overlapping between the ELFA and DAPI emission spectra (Nedoma and Vrba 2006). We demonstrated that the ELF-P labelling treatment did not significantly increase the background noise detected on the flow cytometer. This was not the case with epifluorescence microscopy where a significant background was measured on the filter that had to be subtracted from the ELFA-associated particle fluorescence (Nedoma et al., 2003). This mathematical correction is avoided with flow cytometry and thus decreases the bias linked to counts of ELFA-labelled cells.

We showed that both PI and DAPI can be used to counterstain ELFA-labelled cells. DAPI has the advantage of allowing discriminating the naturally fluorescent phytoplankton cells. PI, as chlorophyll $a$, emits in the red wavelength making the discrimination of autotrophic from heterotrophic cells impossible. It should be noted that only the prokaryotic autotrophic cells will survive the 20,000 g centrifugation step. The potential for combining many fluorochromes should enable more parameters linked with ELFA labelling to be measured. For example, we are currently testing the combination of an in situ hybridization method with ELFA labelling. This protocol would help to assess which phylogenetic bacterial groups are responsible for PA.

The detection of ELFA-labelled bacteria by flow cytometry has been successfully applied on both marine and freshwater samples. In Lake Plešné, we showed that more than $30 \%$ of the heterotrophic bacterial cells $(<1 \mu \mathrm{m})$ were ELFA-positive in all samples. This is the first report of heterotrophic bacterial PA in Lake Plešné. In marine samples, the detection of ELFA labelled cells by flow cytometry enabled us to distinguish two populations of heterotrophic bacteria with different apparent DNA contents. The high DNA bacteria were shown to be representative of "live" cells and nucleoid-containing cells (Li et al., 1995; Gasol et al., 1999; Gasol and Del Giogio, 2000). These high DNA bacteria are the dynamic members of the bacterial community (i.e. actively metabolizing bacteria, Gasol et al., 1995; Gasol and Del Giogio, 2000). We found that the ELFA positive bacteria corresponded to the high DNA bacteria, suggesting that only the dynamic bacteria express PA or possess significant cell specific PA to allow labelling with ELFA. This result suggests that the detection of ELFA precipitates is really linked to enzymatic activity. Contrary to lake samples, we found low percentages of ELFA-labelled bacteria in marine samples, even when considering high DNA bacteria ( $<5 \%$, Fig. $7 b)$. Very low ELFA labelling levels $(<0.01 \%)$ have been previously reported by Van Wambeke et al. (in press) in the Mediterranean Sea $\left(\mathrm{Vm}<15 \mathrm{nM} \mathrm{h}^{-1}\right)$ using a filtration and microscopy detection method. Time kinetic experiment showed 
that after $6 \mathrm{~h}$ incubation, the absolute ELFA fluorescence reached a steady level up to $18 \mathrm{~h}$ (data not shown). Thus, incubating the profile samples for $6 \mathrm{~h}$, we measured the maximum values of ELFA labelling for these samples. Even though we were not able to observe significant variations in the proportion of ELFA-labelled cells with depth, we observed significant variations in ELFA median fluorescence. Consequently, the variation in ELFA median fluorescence was a better indicator of the PA level and P deficiency of heterotrophic bacteria.

In conclusion, the protocol we report in this study enables samples to be prepared for detecting ELFA labelling by flow cytometry. Samples can be preserved up to 4 months before analysis. The separation of cell clumps with Tween 80 and cell precipitation using centrifugation had no significant effect on ELFA labelling parameters or on the recovery of the bacterial cells. The analysis of such samples by flow cytometry allowed quantitative assessment of the phosphatase activity for heterotrophic bacteria in both oligotrophic marine and mesotrophic lake samples. This method promises to improve our understanding of the physiological response of heterotrophic bacteria to $\mathrm{P}$ limitation.

\section{Acknowledgements}

We acknowledge Michel Denis for his help with flow cytometry, and the Plateforme Régionale de Cytométrie pour la Microbiologie (COM, UMS 2196). We thank Michel Lafont and Léna Thomas for the sampling at SOFCOM site, Peggy Rimmelin and Thierry Moutin for their help with the MAGIC25 method and Tracy Bentley for improving the English. We are grateful to the Gordon and Betty Moore foundation. This study was supported by INSU-CNRS through the French program PROOF-PECHE, and by the PAI Barrande project 2005-06-009-01.

\section{References}

Andrade, L., Gonzalez, A.M., Valentin, J.L., Paranhos, R., 2004. Bacterial abundance and production in the Southwest Atlantic Ocean. Hydrobiologia 511, 103-111.

Azam, F., Frenchel, T., Field, J.G., Gray, J.S., Meyer-Reil, L.A., Thingstad, T.F., 1983. The ecological role of water-column microbes in the sea. Mar. Ecol., Prog Ser. 10, 257-263.

Bianchi, A., Giuliano, L., 1996. Enumeration of viable bacteria in the marine pelagic environment. Appl. Environ. Microbiol. 62, 174-177.

Biegala, I.C., Not, F., Vaulot, D., Simon, N., 2003. Quantitative assessment of picoeukaryotes in the natural environment by using taxon-specific oligonucleotide probes in association with tyramide signal amplification-fluorescence in situ hybridization and flow cytometry. Appl. Environ. Microbiol. 69, 5519-5529.

Campbell, L., Liu, H., Nolla, H.A., Vaulot, D., 1997. Annual variability of phytoplankton and bacteria in the subtropical North Pacific Ocean at Station ALOHA during the 1991 1994 ENSO event. Deep-Sea Res., Part I 44, 167-192.

Cotner, J.B., Biddanda, B.A., 2002. Small players, large role: microbial influence on biogeochemical processes in pelagic aquatic ecosystems. Ecosystems 5, 105-121.

Cox, W.G., Singer, V.L., 1999. A high-resolution, fluorescence-based method for localization of endogenous alkaline phosphatase activity. J. Histochem. Cytochem. 47, 1443-1456.

Davey, H.M., Kell, D.B., 1996. Flow cytometry and cell sorting of heterogeneous microbia populations: the importance of single-cell analyses. Microbiol. Rev. 60, 641-696.

Dignum, M., Hoogveld, H.L., Floris, V., Gons, H.J., Matthijs, H.C.P., Pel, R., 2004a. Flow cytometric detection of phosphatase activity combined with ${ }^{13} \mathrm{C}_{-} \mathrm{CO}_{2}$ tracer-based growth rate assessment in phytoplankton populations from a shallow lake. Aquat. Microb. Ecol. 37, 159-169.

Dignum, M., Hoogveld, H.L., Matthijs, H.C.P., Laanbroek, H.J., Pel, R., 2004b. Detecting the phosphate status of phytoplankton by enzyme-labelled fluorescence and flow cytometry. FEMS Microbiol. Ecol. 48, 29-38.

Dyhrman, S.T., Palenik, B., 1999. Phosphate stress in cultures and field populations of the dinoflagellate Prorocentrum minimum detected by a single-cell alkaline phosphatase assay. Appl. Environ. Microbiol. 65, 3205-3212.

Epstein, S.S., Rossel, J., 1995. Enumeration of sandy sediment bacteria: search for optimal protocol. Mar. Ecol., Prog. Ser. 117, 289-298.

Espeland, E.M., Wetzel, R.G., 2001. Effects of photosynthesis on bacterial phosphatase production in biofilms. Microb. Ecol. 42, 328-337.

Gasol, J.M., Del Giogio, P., 2000. Using flow cytometry for counting natural planktonic bacteria and understanding the structure of planktonic bacterial communities. Sci. Mar. 64, 197-224

Gasol, J.M., Del Giorgio, P., Massana, R., Duarte, C.M., 1995. Active versus inactive bacteria: size-dependence in a coastal marine plankton community. Mar. Ecol. Prog. Ser. 128, 91-97.
Gasol, J.M., Zweifel, U.L., Peters, F., Fuhrman, J.A., Hagstrom, A., 1999. Significance of size and nucleic acid content heterogeneity as measured by flow cytometry in natural planktonic bacteria. Appl. Environ. Microbiol. 65, 4475-4483.

Gonzalez-Gil, S., Keafer, B.A., Jovine, R.V.M., Aguilera, A., Lu, S., Anderson, D.M., 1998. Detection and quantification of alkaline phosphatase in single cells of phosphorusstarved marine phytoplankton. Mar. Ecol., Prog. Ser. 164, 21-35.

Grégori, G., Citterio, S., Ghiani, A., Labra, M., Sgorbati, S., Brown, S., Denis, M., 2001. Resolution of viable and membrane-compromised bacteria in freshwater and marine waters based on analytical flow cytometry and nucleic acid double staining. Appl. Environ. Microbiol. 67, 4662-4670.

Hoppe, H.-G., 2003. Phosphatase activity in the sea. Hydrobiologia 493, 187-200.

Huang, Z., You, W., Haugland, R.P., Paragas, V.B., Olson, N.A., Haugland, R.P., 1993. A novel fluorogenic substrate for detecting alkaline phosphatase activity in situ. J. Histochem. Cytochem. 41, 313-317.

Huang C.-T. Xu, K.D., McFeters, G.A. Stewart, P.S, 1998. Spatial patterns of alkaline phosphatase expression within bacterial colonies and biofilms in response to phosphate starvation. Appl. Environ. Microbiol. 64, 1526-1531.

Karl, D., Björkman, K., 2002. Dynamics of DOP. In: Carlson, Hansell (Ed.), Biogeochemistry of Marine Dissolved Organic Matter. Academic Press, pp. 249-366.

Kepner, J.R.L., Pratt, J.R., 1994. Use of fluorochromes for direct enumeration of total bacteria in environmental samples: past and present. Microbiol. Rev. 58, 603-615.

Kopacek, J. Hejzlar J., Borovec, J. Porcal, P. Kotorova, I, 2000. Phosphorus inactivation by aluminum in the water column and sediments: lowering of in-lake phosphorus availability in an acidified watershed-lake ecosystem. Limnol. Oceanogr. 45, 212-225.

Larsson, K., Weibull, C., Cronberg, G., 1978. Comparison of light and electron microscopic determinations of the number of bacteria and algae in lake water. Appl. Environ. Microbiol. 35, 397-404.

Li, W.K.W., Jellett, J.F., Dickie, P.M., 1995. DNA distributions in planktonic bacteria stained with TOTO or TO-PRO. Limnol. Oceanogr. 40, 1485-1495.

Lyman, J., Fleming, R.H., 1940. Composition of Sea Water. J. Mar. Res. 3, 134-136.

Manini, E., Danovaro, R., 2006. Synoptic determination of living/dead and active/ dormant bacterial fractions in marine sediments. FEMS Microbiol. Ecol. 55, 416-423.

Marie, D., Vaulot, D., Partensky, F., 1996. Application of the novel nucleic acid dyes YOYO-1, Yo-PRO-1, and PicoGreen for flow cytometric analysis of marine prokaryotes. Appl. Environ. Microbiol. 62, 1649-1655.

Monaghan, E.J., Ruttemberg, K.C., 1999. Dissolved organic phosphorus in the coastal ocean: reassessment of available methods and seasonal phosphorus profiles from the Eel River Shelf. Limnol. Oceanogr. 44, 1702-1714.

Moutin, T., Thingstad, T.F., Van Wambeke, F., Marie, D., Slawyk, G., Raimbault, P., Claustre, H., 2002. Does competition for nanomolar phosphate supply explain the predominance of the cyanobacterium Synechococcus ? Limnol. Oceanogr. 47, 1562-1567.

Mulholland, M.R., Floge, S., Carpenter, E.J., Capone, D.G., 2002. Phosphorus dynamics in cultures and natural populations of Trichodesmium spp. Mar. Ecol., Prog. Ser. 239, $45-55$.

Nedoma, J., Vrba, J., 2006. Specific activity of cell-surface acid phosphatase in different bacterioplankton morphotypes in an acidified mountain lake. Environ. Microbiol. 8, 1271-1279.

Nedoma, J., Štrojsová, A., Vrba, J., Komárková, J., Šimek, K., 2003. Extracellular phosphatase activity of natural plankton studied with ELF97 phosphate: fluorescence quantification and labelling kinetics. Environ. Microbiol. 5, 462-472.

Ou, L., Huang, B., Lin, L., Hong, H., Zhang, F., Chen, Z., 2006. Phosphorus stress of phytoplankton in the Taiwan Strait determined by bulk and single-cell alkaline phosphatase activity assays. Mar. Ecol., Prog. Ser. 327, 95-106.

Paragas, V.B., Zhang, Y.Z. Haugland, R.P. Singer, V.L, 1997. The ELF-97 alkaline phosphatase subtrate provides a bright, photostable, fluorescent signal amplification method for FISH. J. Histochem. Cytochem. 45, 345-357.

Rengefors, K., Ruttenberg, K.C., Haupert, C.L., Taylor, C., Howes, B.L., Anderson, D.M., 2003. Experimental investigation of taxon-specific response of alkaline phosphatase activity in natural freshwater. Limnol. Oceanogr. 48, 1167-1175.

Rimmelin, P., Moutin, T., 2005. Re-examination of the MAGIC method to determine low orthophosphate concentration in seawater. Anal. Chim. Acta 548, 174-182.

Robertson, B.R., Button, D.K., 1989. Characterizing aquatic bacteria according to population, cell size, and apparent DNA content by flow cytometry. Cytometry 10 , $70-76$.

Robertson, B.R., Button, D.K., Koch, A.L., 1998. Determination of the biomasses of small bacteria at low concentrations in a mixture of species with forward light scatter measurements by flow cytometry. Appl. Environ. Microbiol. 64, 3900-3909.

Ruttenberg, K.C., Dyhrman, S.T., 2005. Temporal and spatial variability of dissolved organic and inorganic phosphorus, and metrics of phosphorus bioavailability in an upwelling-dominated coastal system. J. Geophys. Res. 110

Sgorbati, S., Barbesti, S., Citterio, S., Bestetti, G., De Vecchi, R., 1996. Characterization of number, DNA content, viability and cell size of bacteria from natural environments using DAPI PI dual staining and flow cytometry. Minerva Biotecnol. 8, 9-15.

Strickland, J.D.H., Parsons, T.R., 1972. A practical handbook of seawater analysis. Bull. Fish. Res. Board Can. 167.

Telford, W.G., Cox, W.G., Stiner, D., Singer, V.L., Doty, S.B., 1999. Detection of endogenous alkaline phosphatase activity in intact cells by flow cytometry using the fluorogenic ELF-97 phosphatase substrate. Cytometry 37, 314-319.

Troussellier, M., Courties, C., Zettelmaier, S., 1995. Flow cytometric analysis of coastal lagoon bacterioplankton and picophytoplankton: fixation and storage effects. Estuar. Coast. Shelf Sci. 40, 621-633. 
Van Ommen Kloeke, F., Geesey, G.G., 1999. Localization and identification of populations of phosphatase-active bacterial cells associated with activated sludge flocs. Microb. Ecol. 38, 201-214.

Van Wambeke, F., Christaki, U., Giannakourou, A., Moutin, T., Souvemerzoglou, K., 2002. Longitudinal and vertical trends of bacterial limitation by phosphorus ans carbon in the Mediterranean Sea. Microb. Ecol. 43, 119-133.

Van Wambeke, F., Lefèvre, D., Prieur, L., Sempéré, R., Bianchi, M., Oubelkheir, K., Bruyant, F., 2004. Distribution of microbial biomass, production, respiration, dissolved organic carbon and factors controlling bacterial production across a geostrophic front (Almeria-Oran, SW Mediterranean Sea). Mar. Ecol., Prog. Ser. 269, 1-15.

Van Wambeke, F., Nedoma, J., Duhamel, S., Lebaron, P., in press. Alkaline phosphatase activity studied with ELF97 phosphate: success and limits in P-limited Mediterranean Sea. Aquat. Microb. Ecol. 